Revista de la red interuniversitaria de estudios sobre las literaturas rioplatenses contemporáneas en Francia

7 | 2012

Arqueologías

\title{
La parte maldita
}

\section{Enrique Schmukler}

\section{OpenEdition}

\section{Journals}

\section{Edición electrónica}

URL: http://journals.openedition.org/lirico/755

DOI: $10.4000 /$ lirico.755

ISSN: 2262-8339

Editor

Réseau interuniversitaire d'étude des littératures contemporaines du Río de la Plata

\section{Referencia electrónica}

Enrique Schmukler, « La parte maldita », Cuadernos LIRICO [En línea], 7 | 2012, Publicado el 01 julio 2012, consultado el 22 septiembre 2020. URL : http://journals.openedition.org/lirico/755 ; DOI https://doi.org/10.4000/lirico.755

Este documento fue generado automáticamente el 22 septiembre 2020

\section{(c) (i) (9)}

Cuadernos LIRICO está distribuido bajo una Licencia Creative Commons Atribución-NoComercialSinDerivar 4.0 Internacional. 


\section{La parte maldita}

Enrique Schmukler

\section{REFERENCIA}

Guerriero, Leila (Ed.), Los malditos, Santiago de Chile, Ediciones Universidad Diego Portales, 2011, $475 \mathrm{p}$. 
Ediciones Universidad Diego Portales es probablemente el proyecto editorial más ambicioso de una institución educativa en América Latina, tanto por la calidad de sus libros como por la variedad de las colecciones que alberga. Una de las más singulares es "Vidas Ajenas", dedicada a obras literarias que exploran el tan en boga cruce entre literatura y géneros testimoniales (biografía, autobiografía, biografías ficcionales o imaginarias). En esa colección, con selección y prólogo de la periodista argentina Leila Guerriero, a fines de 2011 se publicó Los Malditos, un volumen de crónicas que reúne los "perfiles" de 17 escritores latinoamericanos cuyo denominador común es un seductor y complejo estigma

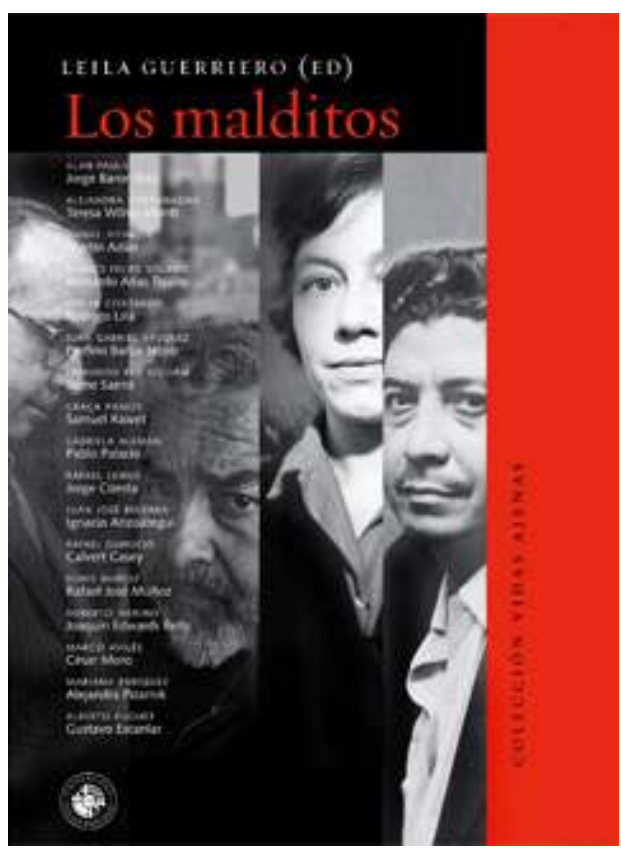
literario: el malditismo. Alan Pauls, Juan Gabriel Vázquez, Juan José Becerra, Alberto Fuguet, Mariana Enriquez, Marco Avilés, Alejandra Costamagna y Rafael Lemus son algunos de los nombres de una lista de escritores y periodistas latinoamericanos que pesquisaron la leyenda maldita de un conjunto de autores del siglo XX y de la primera década de este siglo. Los textos están organizados biográficamente, es decir, respetando una unidad tempo-espacial que une el lugar y la fecha de nacimiento con el momento y el lugar de la muerte. Por lo demás, la intención esencial de los perfiles es "dar a ver" un autor, algo que se prefigura en el título mismo de cada relato, donde una suerte de definición o imagen busca atribuirle a cada "personaje" una singularidad irreductible. Por ejemplo, en la óptica de Alan Pauls, Jorge Baron Biza es "el hombre del subsuelo", tal vez por la propensión del personaje a saciar su alcoholismo en los bares de mala muerte que hay debajo de la avenida 9 de julio, en la ciudad de Buenos Aires ; y para Juan José Becerra, Ignacio Anzoátegui es "el fascista que ríe", definición acuñada por Horacio González, el director de la Biblioteca Nacional Argentina, a quien Becerra entrevistó para construir un perfil que bien podría ser incluido ex cursus en La Literatura nazi en América, de Roberto Bolaño ( junto con el otro fascista maldito de la saga, el boliviano Jaime Saenz, retratado por su coterráneo Edmundo Paz Soldán como "el visitante profundo").

2 Pero estos incipits asedian sin dilucidar el único interrogante que plantean estas 17 crónicas... ¿qué es un escritor maldito ? Sobre esta cuestión mucho se ha escrito y aún resulta difícil dar con una definición del agrado de la mayoría. Leila Guerriero, en el prólogo, ofrece la suya al afirmar que los escritores retratados en el libro vivieron "todos ellos atravesados por diversas formas del padecimiento" y fueron "todos ellos dueños de una obra proteica y poderosa"(11).

[...] padecieron diversos grados de desdicha y de devastación, ya sea por ejercer el sexo a contrapelo del momento y el lugar equivocados, por escribir en contra (de su época, de su circunstancia, de su entorno), por vivir en contra (de su época, de su circunstancia, de su entorno) [...] Vivieron en un mundo que les resultaba demasiado incomprensible o demasiado despreciable o demasiado hostil, y se 
enfrentaron a él con hostilidad, con desprecio, con fragmentación, con fragilidad,

con espanto. (12)

3 Sobre esta doble caracterización no hay, por supuesto, nada que señalar, o por lo menos en lo que atañe a la primera de ellas : la del padecimiento. Independientemente de la forma en que murieron, todos llevaron vidas bastante desdichadas. Para botón de muestra está la vida de Jorge Baron Biza, que se arrojó al vacío en 2001, en la ciudad de Córdoba, luego de casi cuarenta años en que fue haciéndosele carne la tradición suicida de su familia, iniciada por su padre, Raúl Barón Biza, quien en 1964 se disparó un tiro en la sien luego de estampar "la famosa bofetada de vitriolo" (31) sobre el rostro de su madre; o la del poeta chileno Rodrigo Lira que, según cuenta el periodista Óscar Contardo, se laceró hasta morir desangrado en su bañera el día de su cumpleaños número 32 - coda de una corta vida infeliz de fumador de marihuana célibe, confinado por su familia de clase media a instituciones psiquiátricas y sesiones de electroshocks - ; y, por qué no, la del escritor e ingeniero Samuel Rawet, un inmigrante polaco en Brasil, judío errante y solitario absoluto durante toda su vida. Reñido por siempre con su círculo familiar - se ofendió porque para remodelar la casa, sus padres contrataron a otro ingeniero y no a él pues lo creían demasiado brillante para un trabajo tan simple-, encontró la muerte ya convertido en un Diógenes paranoide que trasegaba deshechos por las calles de los barrios bajos de Brasilia, una ciudad cuyos edificios más importantes "calculó" para el célebre arquitecto de vanguardia Oscar Niemeyer. Cuando lo hallaron, su cadáver llevaba pudriéndose varios días en un departamento nauseabundo, sin luz y sin agua, un sobre de sopa Knorr sobre la mesa y dos libros : uno en inglés y otro en francés.

4 Vidas como éstas se repiten a lo largo de las 475 páginas de Los malditos. La lectura sucesiva de una vida trágica tras otra amplía aún más el espacio de las preguntas : ¿En la desdicha anida realmente el núcleo del malditismo? ¿La desdicha y el padecimiento, cuando son escritores $\mathrm{u}$ hombres de letras quienes los sufren, los convierten automáticamente en escritores malditos? ¿O se trata acaso de la forma elegida para vivir esa desdicha lo que torna maldito a un escritor? ¿Hay alguna relación entre la calidad literaria y el sufrimiento ? Y sobre todo, ¿existe alguna otra definición para un autor maldito ? En el prólogo, Guerriero subraya que otra característica que comparten todos los autores, además de la del padecimiento, es la dispersión de su producción literaria : “[...] tienen una obra contundente (que, en la mayoría de los casos, aunque con notorias excepciones, está olvidada y/o es inconseguible" (12).

5 Vale la pena detenerse en este aspecto porque pondría en entredicho el romanticismo con el que por lo común se lee el padecimiento esencial de estos escritores : como una forma de la heroicidad o del martirio. En "Martín Adán, la vida de cartón", la crónica que indaga la vida del novelista y poeta peruano Rafael de la Fuente, alias Martín Adán, Daniel Titinger presenta a su personaje real comentando el valor y la brillantez de $L a$ casa de cartón. Esa “¿novela ? ¿poema en prosa ? ¿quién sabe qué ?” (66) que sería genial, además, por su precocidad rimbaldiana : "La casa de cartón siempre me había parecido [...] una obra de ingenio desmesurado y maravilloso, sobre todo si había sido escrita por un niño de de dieciséis años. Me gustaba el ritmo : la música de las palabras"(67).

Pero La casa de cartón se publicó en 1927 y Martín Adán falleció el 29 de enero de 1985. En los casi sesenta años que van de una fecha a la otra Adán, esquizofrénico y alcohólico, pasó la mayor parte del tiempo internado por decisión propia en un manicomio y cada vez que salía, también por que se le antojaba, porque ya era hora de 
salir, iba directo a los bares cuyo cobijo abandonaba para volver a internarse en el manicomio. En esa dinámica la literatura seguía existiendo pero adoptaba otra forma, dominada por una intensidad que no le hacía espacio sino como apéndice de una vida demasiado cerrada sobre sí misma. Hasta los años '50, Adán publicó algunos libros de poesía que iban siendo cada vez más herméticos con el avance de la esquizofrenia que, junto con el alcoholismo, se preparaba para devorarlo por entero. Desde esa fecha aproximada hasta el final de sus días no volvió a publicar pero nunca dejó de escribir. ¿Pero dónde escribía? Apelando a cierta mitología del poeta enthousiasmé $e^{1}$, Titinger escribe :

Cuentan que se lo veía borracho en alguna cantina de mala muerte, escribiendo en servilletas o en libretas negras o en la platina de las cajetillas de cigarrillos; en cualquier superficie de papel cuando lo atacaba, de pronto, la poesía" (68).

7 Adán terminó entonces escribiendo en cualquier lado. Sin embargo, la dispersión no es propiedad exclusiva de un genio inconstante. La obra es errática aun en casos como el de Porfirio Barba Jacob quien, según narra Juan Gabriel Vázquez en "Porfirio Barba Jacob : el reino estéril de las lágrimas", el sexto perfil de Los Malditos, tuvo siempre la obsesión de construir una Obra total. A ello obedece tal vez que no haya "publicado" sus poemas en servilletas sino en diarios y revistas que por otra parte muchas veces él mismo creaba o dirigía en los países en los que recalaba. ¿Pero qué fue lo que hizo finalmente que esta Obra Completa no viera la luz en vida de su autor ?' Su historia tal vez no sea del todo desconocida pues existe una gran biografía de Fernando Vallejo ${ }^{3}-$ Vázquez, por supuesto, la cita como fuente en varios pasajes de su texto - que se ocupa de ella magistralmente. Barba Jacob no pudo evitar la irradiación caótica de su producción porque ya no sólo su obra sino él mismo era un escritor ejemplar en el arte de la fuga (probablemente el más errabundo de los poetas de toda la historia literaria de América Latina, anota Vázquez en su texto).

8 En cualquier caso, habría que agregar, la dispersión de la obra de Porfirio Barba Jacob obedeció precisamente a que llevaba una vida errante y no a su irresponsabilidad literaria. Y allí pareciera albergarse otra particularidad bastante frecuente en esta clase de autores, más allá de la tragedia : la relación que mantienen con su propia literatura. Porfirio Barba Jacob viajaba o se fugaba y, con él, lo hacían sus poemas sometiéndose al ritmo de su vida. Martín Adán se emborrachaba o se enloquecía y sus poemas no podían más que sobrevivir en el espacio inconcluso de la locura, o en los sótanos y en los desvanes de los bares y en los ojos ocasionales de los compañeros de Pisco o Inca Cola. Los ejemplos se suceden : al momento de suicidarse, la familia de Rodrigo Lira -que no fue un poeta nómade pero, se lee en su perfil, fue "un escolar nómade", pensaba que los poemas de este joven que "estudió en la universidad pero nunca terminó una carrera, fue poeta pero nunca publicó un libro en vida, se enamoró pero nadie le recuerda una novia" (123), no valían nada. Esos poemas se publicaron recién después de su muerte : "Luego de reunir un conjunto de textos desperdigados, tres de sus amigos lograron publicar, en 1984, el libro Proyecto de obras completas, con prólogo de Enrique Lihn" (124), escribe Óscar Contardo.

9 ¿No se despliega acaso en las cuatro palabras de ese título póstumo toda la ironía que define la relación que los llamados "malditos" entablan con sus libros, sus poemas o sus textos? Sucede que la obra no se revela aquí como proyecto irrealizado sino al revés : lo irrealizado cristaliza como la cifra del valor del programa literario maldito. En definitiva todo ocurre como si ya no el poeta o escritor maldito fuera un sobreviviente, sino su obra literaria que, ilegible o no, le sigue los pasos como puede. Y todo esto 
teniendo en cuenta que siempre se trata de escritores para quienes la escritura (o la no escritura) ocuparía o debiera ocupar el lugar central. Pero he aquí una paradoja: la obra sobrevive en la medida en que se acopla a la vida que la opaca. La relación entre ambas esferas aparece dada vuelta, invertida. Y la prueba de este giro la dan casos como el Proyecto de Obras de completas de Lira, tan similar al de Poesía Completa de Barba Jacob recopiladas por Fernando Vallejo.

10 En su texto, Juan Gabriel Vazquez no menciona este otro "proyecto" de obra completa aunque vale la pena citarlo. El plan de Vallejo era escribir la biografía de Porfirio Barba Jacob y de hecho lo consiguió con creces. Ahora bien, en el momento de ir en busca del autor maldito fue recabando y recolectando los poemas que se creían perdidos. Esos textos estaban dispersos, se habían diluido... en la vida. Y, al escribir la vida, afloraron como huellas de su derrotero. El resultado: que la Poesía Completa de Porfirio Barba Jacob compilada por Fernando Vallejo surge tocada por la experiencia del poeta, que es su caución. Y una última derivación : en el proceso de reflotar la obra también el poeta, tan indisoluble de los textos recobrados, adquiere dimensión de obra, es decir: de personaje. Buena parte de los autores explorados en Los malditos entablan esta relación de proximidad con su obra, "viven" de esa zona de contacto que los vuelve a ellos también creaciones imaginarias como sus propios escritos.

11 Pero la percepción de los autores como siluetas imaginarias no es sólo obra de una tercera persona. Son también los malditos quienes practican una "mutilación narcisista" (para esbozarlo en los términos con que César Aira se refiere a Lucio V. Mansilla ${ }^{4}$ ) a través de un gesto simple - pero que muchas veces se piensa lúdico- y cuyo modelo ilustre sería Lautréamont ${ }^{5}$ : el trabajo de desfiguración que casi todos los autores retratados comparten y que tiene como blanco de mira el nombre propio. Los malditos se inventan pseudónimos o heterónimos y, en no menos un tercio del total de los autores retratados, ese gesto se repite ya como parte de un exhibicionismo intencional, ya como un destello sutil. Si en ciertos casos se los adopta como un destino (Flora Pizarnik transformada en Alejandra para la posteridad, o Alfredo Quíspez Asín Mas alias César Moro), en otros es la marca del goce por una alteridad proliferante lo que prevalece (el campeón en esta materia es, otra vez, Porfirio Barba Jacob "que de niño y de joven fue Miguel Angel Osorio, que durante un breve tiempo fue Maín Ximenez y luego, durante un tiempo no tan breve, Ricardo Arenales [...], que al final de su vida llegó a pensar en llamarse Juan Pedro Pablo" (151). Claro que a veces la operación es menos visible, como en el caso del supracitado Jorge Baron Biza quien modifica su primer apellido "olvidando" inscribir el acento agudo del Barón patronímico, en una intervención que manifestaría cierta cautela, como si fuera una supresión que se pretendiera sin importancia. Nada más lejos de la realidad, apunta Alan Pauls : "Su vida es un caso dramático de portación de apellido, una lucha incesante con y por el nombre" (27).

12 Se diría que el trabajo imaginario sobre el nombre propio aquí es substancial. Más que el síntoma de una pulsión maldita de auto-flagelación, la invención de un nombre nuevo obedecería a la temprana conciencia de un deseo : el de inscribirse en el terreno de la ficción erigiendo al yo en personaje literario. De esa ambición se hace eco Los malditos. Sin la excentricidad que posibilitan las vidas de escritores que pueden ser elevados a la categoría de personaje, es decir de mito, la tarea de estos diecisiete retratistas no hubiera tenido éxito alguno. 


\section{NOTAS}

1. El también trágico Edgard Zilsel contextualiza de manera magistral las distintas figuras del genio -entre ellas la del poeta- en su fundamental Le Génie. Cf. E. Zilsel, Le Génie. Histoire d'une notion de l'antiquité à la rennaissance, Paris, Editions de Minuit, 1993.

2. Fernando Vallejo en el prólogo a las Obras Completas de Porfirio Barba Jacob desarrolla la obsesión que persiguió al poeta durante toda su vida. Escribir un solo, gran libro de poemas al que iba imaginando con diferentes títulos y estructuras a medida que pasaban los años y no lo escribía. Cf. P. Barba Jacob, Poesía Completa, México, Fondo de Cultura Económica, 2007.

3. F. Vallejo, Porfirio Barba Jacob, el mensajero, Madrid, Alfaguara, 2008.

4. C. Aira, "Mutilación narcisista", prólogo a L.V. Mansilla, Esa cabeza toba y otros textos, Buenos Aires, Mate, 2001.

5. A este respecto es ejemplar el análisis de la heteronimia, la asteronimia y la pseudonimia de Jean-Luc Steinmetz en el prefacio de las Obras Completas de la colección de La Pléiade. Cf. J.-L. Steinmetz, « Préface », in Lautréamont, Euvres Complètes, La Pléiade, 2009, p. X-XL.

\section{AUTORES}

\section{ENRIQUE SCHMUKLER}

Université Paris 8 